\author{
Cadernos de \\ ESTUDOS LNGUUISTICOS - (59.1), Campinas, pp. 175-196 - jan./abr. 2017
}

\title{
TEXTO, CONTEXTO E CONSTRUÇÃO DA REFERÊNCIA: PROGRAMAS TELEVISIVOS BRASILEIROS EM FOCO
}

\author{
ANNA CHRISTINA BENTES* \\ BEATRIZ FERREIRA-SILVA** \\ ANA CECÍLIA ALMEIDA ACCETTURI ${ }^{* * *}$
}

\begin{abstract}
RESUMO: Ao longo deste artigo, com base nas reflexões desenvolvidas em trabalhos anteriores do nosso grupo de pesquisa sobre os programas televisivos Manos e Minas e Conexões Urbanas e com base na articulação de postulações dos campos de estudos do texto e do discurso, da antropologia linguística e da sociologia, buscaremos responder as seguintes perguntas: (i) quais tipos de ancoragem possibilitam a construção referencial que é, em parte, responsável pela emergência de determinadas categorizações e também pela identidade social dos programas?; (ii) como essas ancoragens podem propiciar uma melhor compreensão sobre as relações entre a construção referencial dos/nos programas e o contexto social mais amplo a partir do qual essas específicas configurações genéricas emergem? Para tanto, partimos de uma concepção ampliada de texto, considerando que os programas televisivos em análise apresentam uma dimensão textual de caráter multimodal. Sendo assim, trataremos nesse artigo dos processos de ancoragem, considerados aqui como processos (con)textuais, enfocando a questão da introdução referencial.
\end{abstract}

Palavras-chave: categorização; processos de ancoragem; multimodalidade; referência;

ABSTRACT: In this article, based on analysis of brazilian television programs developed in previous works of our research group and also based on postulates of text and discourse studies, linguistic anthropology and sociology, we will try to answer the following questions: (i) what types of anchoring allow referential construction that is partly responsible for the social identity of the programs and also for the emergence of certain categorizations within those same programs? (ii) how can these anchorages provide a better understanding of the relationship between the referential construction of the programs and the larger social context from which these specific generic configurations emerge? In order to do so, we start from an expanded conception of text, considering that television programs present a textual dimension of multimodal nature. Thus, we will deal in this article with anchoring processes, considered here as (con) textual processes, focusing on the issue of referential introduction. Keywords: categorization; anchoring process; multimodality; reference.

\footnotetext{
*Universidade Estadual de Campinas, Campinas (SP), Brasil.anna@iel.unicamp.br

** Universidade Estadual de Campinas, Campinas (SP), Brasil. beatriz.ai@gmail.com

${ }^{* * * *}$ Universidade Estadual de Campinas, Campinas (SP), Brasil. ana.cecilia_13@hotmail.com
} 


\section{INTRODUÇ̃̃O}

Os anos de 2007 e 2008 foram particularmente marcantes em relação à ampliação, na grande mídia brasileira, da presença dos grupos sociais das periferias do País: em 2007, pela primeira vez, o rapper Mano Brown, um dos mais importantes protagonistas do campo da produção cultural da periferia ${ }^{1}$ paulista e brasileira, foi entrevistado pelo então prestigiado programa Roda Viva, da emissora pública aberta TV Cultura; no primeiro semestre de 2008, a mesma emissora iniciou o Manos e Minas, um programa semanal que se propunha a "trazer a voz da periferia para a grande mídia" (GRANATO, 2011) e no interior do qual protagonistas do campo da produção cultural da periferia não eram somente ouvidos como convidados e como participantes do auditório, mas também assumiram os papéis de apresentadores do programa, como os rappers paulistas Rappin Hood, Thaíde e Max B.O; no segundo semestre de 2008, o canal de TV por assinatura Multishow deu início ao programa Conexões Urbanas, que se propunha a ser visto como um tipo de "TV ação", cujo objetivo era o de "mostrar transformações sociais bem-sucedidas" (BENTES, MARIANO E ACCETTURI, 2015), e que tinha como coordenador o fundador do grupo cultural AfroReggae, José Júnior, agente prestigiado do campo cultural da periferia carioca e brasileira.

Ao longo deste artigo, com base nas reflexões desenvolvidas em trabalhos ${ }^{2}$ anteriores do nosso grupo de pesquisa sobre os programas televisivos citados, e também com base na articulação de postulações dos campos de estudos do texto e do discurso, da antropologia linguística e da sociologia, buscaremos responder as seguintes perguntas: (i) quais tipos de ancoragem possibilitam a construção referencial que é, em parte, responsável pela emergência de determinadas categorizações e pela identidade social dos programas?; (ii) como essas ancoragens podem propiciar uma melhor compreensão sobre as relações entre a construção referencial dos/nos programas e o contexto ${ }^{3}$ social mais amplo a partir do qual essas específicas configurações genéricas emergem?

${ }^{1}$ Acerca do significado de "periferia", assumimos aqui a perspectiva discutida por Nascimento (2011), para quem uma abordagem relacional se aplica ao conceito de "periferia", haja vista que os discursos circulantes hoje em dia enunciam a periferia não apenas em oposição a uma centralidade geográfica, mas também como denotativa de "uma certa realidade social concreta, inscrição étnicoracial ou de classe social, referência para uma atuação político-cultural, sentimentos positivos de pertencimento e afetividade" (NASCIMENTO, 2011: 204).

${ }^{2}$ Bentes (2009; 2011); Granato (2011); Bentes e Ferrari (2013); Bentes; Mariano; Ferreira-Silva (2013); Mariano (2014); Ferreira-Silva (2015); Accetturi (2015); Bentes; Mariano; Accetturi (2015; 2017). Todos os trabalhos referidos anteriormente desenvolveram-se no âmbito dos projetos FAPESP Proc. 2009/08369-8 e CNPq Proc. 309845/2013-0.

${ }^{3}$ No âmbito desse artigo, assumiremos a noção de contexto postulada por HANKS (2008), caracterizada por ser uma noção gradiente, que comporta aspectos emergenciais e estabilizados e que se instaura em função da necessária arbitragem entre aspectos sociais e culturais de âmbito micro e macro e no diálogo com abordagens sociocognitivas da linguagem (VAN DIJK, 2014). Retomamos também algumas das discussões empreendidas a respeito da noção de contexto e da questão da multimodalidade desenvolvidas em Bentes (2008; 2011), Koch; Morato; Bentes (2011). 
Para tanto, partimos de uma concepção ampliada de texto, considerando que os programas televisivos em análise apresentam uma dimensão textual de caráter multimodal. Sendo assim, trataremos neste artigo dos processos de ancoragem, considerados aqui como processos (con)textuais, enfocando a questão da introdução referencial.

A noção de ancoragem é muito importante para a compreensão dos processos referenciais que auxiliam na estruturação de práticas discursivas. Ela é assumida, por exemplo, por autores brasileiros como Koch (2002; 2004; 2008), Marcuschi (2005) e Cavalcante (2005). Essa noção é formulada por Prince (1981) e envolve a distinção entre a introdução de um objeto-de-discurso não-ancorado (totalmente novo) no texto e um ancorado (dado, conhecido, associado a elementos presentes no co-texto ou no contexto sociocognitivo).

Para os interesses deste trabalho, assumimos aqui as postulações de Marcuschi (2005) sobre a introdução referencial, baseadas nas formulações de Monika Schwarz sobre essa questão. Para esses autores, a introdução referencial pressupõe um processamento textual que ocorre fundamentalmente por meio da mobilização de anáforas indiretas. Tomamos também as formulações de Mondada (1994), que concebe a produção da referência por meio de práticas multimodais e não somente por meio de práticas linguísticas. Por fim, retomamos alguns pressupostos enunciados em Bentes; Rio (2005), Bentes (2008) e Bentes; Ramos; Alves Filho (2010), a propósito da análise de processos de referenciação considerando dados interacionais e de natureza multimodal (KRESS; VAN LEEUWEN, 2010).

Nossa hipótese é a de que os processos de ancoragem multimodal, dada a natureza dos gêneros analisados (BAKHTIN, 2003), programas televisivos, possibilitam que eles também possam ser vistos como referências multimodais, podendo, assim, ser percebidos como entidades discursivas que resultam de um trabalho sócio-semiótico e textual-discursivo contínuo com fins de consumo simbólico (JENKINS, 2006). Essa postulação pretende contribuir para a exemplificação das relações entre texto, gênero e contexto, relações essas que podem ser vistas como necessariamente graduais, mediadas e sóciocognitivamente ancoradas. (BENTES; REZENDE, 2014; MORATO, 2012; CAVALCANTE, 2011).

Para tanto, faremos o percurso que vai da apresentação de aspectos do contexto social mais amplo, no qual se dá a emergência dos programas Manos e Minas e Conexões Urbanas, até a elaboração de análises do fenômeno da introdução/ativação de referentes nas partes iniciais de episódios de cada um dos programas citados. Com isso, acreditamos ser possível mostrar como a construção referencial desses programas é uma prática de linguagem de natureza multimodal que necessariamente implica processos de contextualização/ancoragem no curso de sua realização.

Para a descrição do contexto social mais amplo, apresentaremos alguns aspectos dos trabalhos de Pochmann (2012) e Souza (2012) sobre a ascensão dos grupos sociais que compunham as camadas baixas e médias no Brasil e de seu contato com novas situações e novas práticas multimodais de linguagem. 
Para a análise do fenômeno da construção dos programas televisivos mencionados como referências multimodais e sociais a partir da observação do fenômeno da ancoragem, consideraremos as partes iniciais (que duram em média um minuto) de um episódio do Manos e Minas, de 2008, e de um episódio do Conexões Urbanas, também de 2008.

\section{CONTEXTOS DE EMERGÊNCIA DE UMA (NOVA) FRAÇÃO DE CLASSE}

São vários os estudos brasileiros que se têm voltado para explicação e para descrição do surgimento de novas frações de classe no Brasil. Dentre esses estudos, destacam-se os de Pochmann (2012) acerca da chamada "nova classe média" e os estudos de Souza (2012) sobre "uma nova classe trabalhadora" em desenvolvimento no País, especialmente a partir dos anos 2000.

O trabalho de Pochmann (2012) se volta para uma série de levantamentos estatísticos sobre renda e trabalho, apresentando índices sobre o crescimento do trabalho ligado às artes, às humanidades e aos elementos de prática comunicacional e religiosa, por exemplo. Esse crescimento é, segundo o autor, também marcado pela incorporação de negros, pretos e pardos aos postos de trabalho.

A nosso ver, as ocupações geradas pelas práticas de produção cultural da periferia, de modo geral, relacionam-se a postos de trabalho como os mencionados acima, se considerarmos os agentes e agitadores culturais, os escritores e comunicadores, os desenvolvedores de oficinas e de cursos, os funcionários ligados às congregações religiosas presentes na periferia, os artistas plásticos e musicais, como os grafiteiros e os rappers, cujas trajetórias profissionais estão relacionadas ao movimento hip hop. Tais indicadores remetem a essas populações não brancas que, secularmente, têm habitado as periferias do País. Os trabalhos congregados pela Cooperifa, na periferia paulistana, de acordo com Nascimento (2011), são um exemplo desse tipo de ocupação profissional. Segundo a autora, as iniciativas do Sarau da Cooperifa resultaram em oportunidades de agregação de artistas e ativistas de diferentes estéticas e proporcionaram a consolidação de novos grupos produtores e consumidores de bens culturais do movimento de literatura marginalperiférica e de outros movimentos culturais.

Já o trabalho de Souza (2012) apresenta-se como discussão crítica a uma compreensão economicista acerca do que constituiria uma classe social, ao mesmo tempo em que se volta para uma reconstrução das condições e das práticas que, segundo o autor, propiciaram, à custa de muito esforço pessoal, a ascensão de uma nova classe de trabalhadores. ${ }^{4}$ Conforme Souza (2012), ao assumirmos que

${ }^{4}$ Neste caso, Souza (2012) recusa a ideia de ascensão de uma "nova classe média" e defende a emergência de uma "nova classe trabalhadora", não propriamente identificada em semelhança às práticas de uma nova classe média, sobretudo se considerarmos a precarização da atividade laboral e das relações familiares e sociais desses grupos ascendentes, práticas essas que foram analisadas na obra do autor. 
as classes sociais se expressam muito mais por «uma visão de mundo 〈prática»» manifestada nos comportamentos e atitudes, é preciso que tenha havido não apenas incremento da renda e do consumo, mas também a incorporação de novas práticas e, nos termos de Bourdieu (1996), de novas disposições para agir.

Quanto a essa possível alteração nas disposições e práticas dos indivíduos, consideramos que o contato com movimentos culturais como o hip hop, com a literatura marginal-periférica e com outras produções culturais da periferia pode significar para os indivíduos ligados à produção cultural uma oportunidade para o desenvolvimento de novas disposições em relação à autoestima, autoconfiança e autodisciplina ${ }^{5}$, haja vista que as práticas culturais desenvolvidas por membros de grupos periféricos levam não apenas à fruição cultural, mas também à criação (SOUZA, 2012; SILVA, 2012). Nesse sentido é que se pode compreender a decisão de diversos jovens e adultos de se ligarem de modo mais estreito à produção cultural e de se dedicarem à dimensão simbólica da vida social.

A nosso ver, os levantamentos quantitativos acerca da renda e das relações de trabalho descritos por Pochmann (2012) como indicadores de uma nova fração de classe, quando complementados pela reconstrução de Souza (2012) e de Nascimento (2011), remetem à ascensão de uma fração de classe nos anos 2000. Consideramos que a fração de classe que ascende pode ser relacionada aos grupos sociais das periferias urbanas de grandes cidades brasileiras, como São Paulo e Rio de Janeiro, grupos estes que galgaram novas posições econômicas e simbólicas no espaço social por meio de uma conversão de seu capital cultural em bens culturais.

Desse modo, o aumento das ocupações relacionadas à produção cultural (já existente) da periferia proporcionou uma conjuntura capaz de fazer com que o campo da produção cultural da periferia passasse a oferecer oportunidades de empreendimento, de trabalho e de tomadas de posição dos sujeitos no interior de outros campos sociais. A nosso ver, essa ascensão de uma determinada fração de classe demandou uma nova representação midiática para os grupos sociais periféricos, que passaram a ganhar espaço e, consequentemente, maior legitimação ${ }^{6}$ nos campos midiático e jornalístico.

\footnotetext{
${ }^{5}$ Importa ressaltar que essas disposições às quais aludimos, especialmente aquelas ligadas à cultura dos indivíduos, consistem também em traços significativos para o desenvolvimento identitário dos sujeitos e podem estar relacionadas ao seu reconhecimento enquanto sujeitos de grupos específicos. Como exemplo desse reconhecimento identitário promovido pela produção cultural, talvez valha notar o aumento na parcela da população brasileira que se autodeclarou parda ou negra, em 2014, passando a corresponder a $53 \%$ dos brasileiros, diante de $45,5 \%$ que se disseram brancos.

${ }^{6}$ Bentes (no prelo), ao tratar de recursos textuais e discursivos como estratégias de legitimação social, afirma: "Acreditamos que se, por um lado, a legitimação social em relação a determinados atores ou práticas sociais por parte de determinados grupos sociais, especialmente por parte da classe dominante, caracteriza-se pelo reconhecimento e atribuição de distinção a esses atores ou práticas, por outro lado, é preciso que essas práticas legitimadas a partir de um trabalho social conjunto sejam continuamente reiteradas e colocadas em jogo. Sendo assim, é possível afirmar que se há reconhecimento de/ e atribuição de um valor social distinto a determinados atores e práticas sociais é porque há também um trabalho contínuo por parte dos atores sociais para manter a posição legítima que passaram a ocupar no interior de um determinado campo".
} 
Assim, é possível afirmar que, nessa primeira década do século XXI, a indústria cultural brasileira descobriu que a representação midiática da periferia consistia em uma importante pauta ${ }^{7}$ a ser trabalhada no interior de seu aparato comunicacional. Exemplos de configurações dessa nova pauta são: a presença do rapper Mano Brown no programa Roda Viva da TV Cultura em 2007 e a criação de programas voltados para a cultura urbana, a cultura de rua, o movimento hip hop e para iniciativas sociais empreendedoras, como é o caso dos programas Manos e Minas (TV Cultura) e Conexões Urbanas (Multishow).

Interessa notar que esse contexto de mudança social e de ascensão de novas frações de classe indicia não apenas novas representações midiáticas, como também novas práticas discursivas de natureza multimodal no interior do campo jornalístico, uma vez que os atores sociais ${ }^{8}$ do campo cultural da periferia passam a ter um maior protagonismo e também passam a ser mais tematizados, referidos e legitimados no interior desse mesmo campo (o jornalístico), que tem historicamente servido como (des)legitimador das suas práticas e vivências (BOURDIEU, 1997)

Portanto, acreditamos que observar a construção dessas representações midiáticas como novas referências sociais pode auxiliar na compreensão da construção da referência como um processo complexo e necessariamente constituído por processos contextuais de várias ordens, tais como pretendemos mostrar em seguida.

\section{A CONSTRUÇÃO DO PROGRAMA MANOS E MINAS COMO UMA REFERÊNCIA MULTIMODAL E SOCIAL}

Imaginemos que é a primeira vez que ligamos a TV para assistir ao programa de auditório Manos e Minas. O começo do programa ocorre como em muitos outros programas televisivos (sejam de auditório ou não): com uma vinheta de abertura. De acordo com Granato (2011), a estruturação da vinheta de abertura do programa

7 Bentes; Ferrari (2013) analisaram a construção da experiência social por meio das categorizações presentes em uma edição do programa Manos e Minas. Segundo as autoras, o programa tem como tópico discursivo recorrente, por exemplo, as questões de trabalho: "fala-se muito do trabalho que todos desenvolvem, mas também fala-se da falta dele, o que reforça o duplo objetivo geral do programa: mostrar o que o povo da periferia faz e por quais dificuldades passa" (BENTES; FERRARI, 2013, p. 81).

${ }^{8}$ Assumimos aqui as postulações de Bourdieu (1983), para quem os atores sociais realizam suas práticas no interior de um campo, onde adquirem interesses, constroem estratégias e fazem escolhas delineadas pelo habitus internalizado durante sua trajetória de vida. Moura; Silva (2008) afirmam que no Brasil, a partir do final dos anos 1970, "atores sociais tradicionalmente marginalizados da cena política passam não apenas a ocupar o "palco", mas, principalmente, são objeto de uma ressignificação a partir de modelos interpretativos que os valorizam e, no limite, põe-nos como protagonistas da mudança de um país caracterizado por profundas desigualdades e dominações" (p. 45). Acreditamos que esse é o caso da proposta do programa Conexões Urbanas que se constitui como um tipo de modelo interpretativo que confere legitimidade aos principais protagonistas das mudanças sociais pelas quais vem passando o país desde sua redemocratização, especialmente no período em que o programa foi criado e exibido. 
Manos e Minas é composta por elementos visuais, sonoros e verbais identificados com a cultura hip hop. Os elementos visuais constituem-se de imagens (estáticas e em movimento) produzidas a partir da estética do grafite, conforme pode ser observado nas imagens abaixo, recortadas da vinheta do programa:
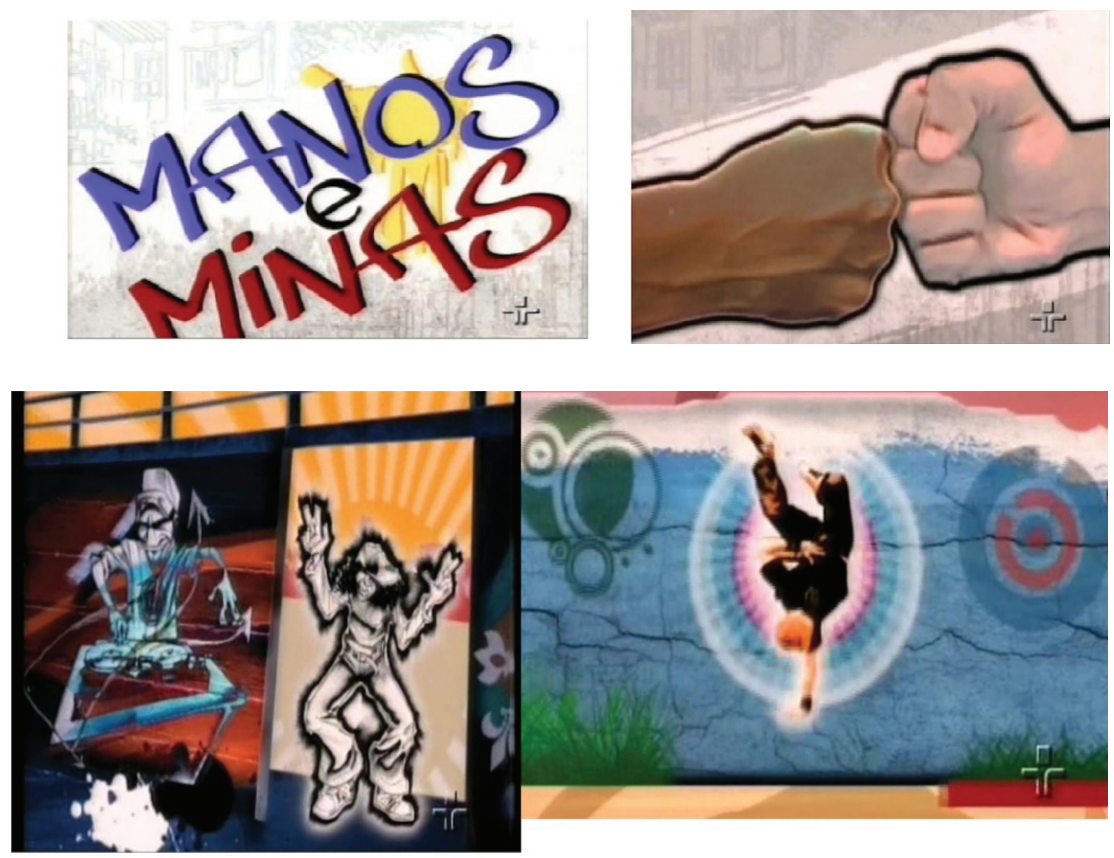

Figura 1: Cenas da vinheta do programa Manos e Minas

Por meio do estudo de Granato (2011), foi possível observar como as diferentes semioses visuais, sonoras e verbais presentes na vinheta de abertura do programa convergem para os objetivos do Manos e Minas, a saber, o de divulgar e o de valorizar as práticas relacionadas à cultura urbana e hip hop no país. A autora salienta, com base em Schiavoni (2008), que as vinhetas possuem um funcionamento importante para a criação de uma identidade para os programas de televisão. Sendo assim, a vinheta do programa constitui-se como "uma das formas de categorização do programa Manos e Minas, construindo-o como um objeto-de-discurso, categorizado e recategorizado em cada uma de suas versões" (GRANATO, 2011, p. 86).

Além disso, a vinheta é em si um objeto de discurso necessariamente ancorado em alguns conhecimentos estruturados por práticas sociais específicas, tais como aquelas que implicam os elementos fundamentais da cultura e/ou movimento hip hop, a saber, os grafiteiros, os MCs (rappers), os DJs (músicos) e os b-boys e b-girls (dançarinos/as de break). A vinheta, como dissemos acima, trabalha com esses elementos para compor o desenho do nome do programa, escrito como os grafites de rua, como para selecionar as imagens que são mostradas. 
Caso os conhecimentos acima mencionados não sejam necessariamente ativados pelo telespectador, a vinheta introduz, então, um referente novo, dado que o telespectador se depara com uma estética específica, que pode não fazer parte de suas práticas sociais e culturais, apesar de ser uma estética bastante divulgada nos grandes centros urbanos e nos meios de comunicação digitais.

Mesmo que o telespectador seja um membro de comunidades periféricas urbanas e que tenha contato constante com a cultura e/ou o movimento hip hop, a vinheta do programa pode continuar funcionando como um introdutor referencial, dado que o programa é apresentado a partir da seleção de uma variedade de recursos semióticos combinados entre si que configuram sua apresentação para o telespectador.

Ainda sobre a vinheta, é importante focar no aspecto verbal de sua composição: dois nomes núcleos genéricos, ligados pela conjunção aditiva "e": Manos e Minas. Por um lado, o nome do programa promove a rotulação de determinados atores sociais. Por outro lado, separadamente, "mano" e "mina" também se constituem em formas de tratamento coloquiais regionalmente marcadas, referindo principalmente os moradores da capital do estado de São Paulo. Essa dupla função (referencial e interacional) das formas nominais que compõem o nome do programa e a sua imersão nas práticas sociais e culturais acima mencionadas auxiliam na introdução multimodal e socialmente ancorada dos principais referentes, a saber, os atores sociais enfocados pelo programa, "os manos e minas da quebrada", "o povo da periferia".

O início do Manos e Minas propriamente dito também se configura como um reforço à sua identidade, voltada para as questões sociais e culturais das periferias das grandes cidades, especialmente da cidade de São Paulo. Em primeiro lugar, seu apresentador é um rapper, Rappin Hood, nome artístico de Antônio Luiz Júnior. O conhecimento sobre sua trajetória ${ }^{9}$ é fundamental para a compreensão da imagem que se quer construir do programa. A estreia de Rappin Hood na TV ocorreu em 2007, quando fazia reportagens acerca das vivências da periferia e de sua cena cultural para o programa Metrópolis, da TV Cultura, no quadro intitulado Mano a Mano. O contato com a TV Cultura se acentuou em 2008, quando o rapper passou a apresentar ${ }^{10}$ o programa Manos e Minas.

${ }^{9}$ Antônio Luiz Júnior nasceu em 1971, na cidade de São Paulo. Foi criado na Vila Arapuá, região pertencente à subprefeitura do Ipiranga e próxima ao bairro Cidade Nova Heliópolis, conhecido como uma das maiores favelas da capital paulista. Segundo Granato (2011, p. 75), aos 11 anos Rappin Hood já participava de atividades musicais na escola, tinha aulas de trombone e corneta, quando começou seu contato com o hip hop. Fez parcerias com grupos importantes do hip hop brasileiro (como com a equipe de bailes Chic Show e com o grupo Racionais MC's) e formou o grupo Posse Mente Zulu, com o qual gravou em 1998 seu primeiro registro. Já em 2001, em carreira solo, o rapper lançou o álbum Sujeito Homem, no qual a mistura entre diferentes musicalidades, como reggae, rap e samba foi reconhecida como uma de suas principais características.

${ }^{10}$ Granato (2011, p. 70) destaca uma entrevista de divulgação do novo programa ao site Radar Cultura, na qual o rapper anuncia: "-Poesia da periferia, a voz da periferia. E segue afirmando -E é muito bom trazer esse público, essa cultura pra tevê. É uma responsabilidade, né? Ser representante do povo na tevê, poder trazer essa cultura, poder tratar o povo da periferia e fazê-los se verem representados na tevê. É uma oportunidade única, assim, que eu só tenho que agradecer". 
A escolha estratégica de Rappin Hood como apresentador é consistente com o tipo de representatividade que se quer construir para o programa. É como se ele "encarnasse" uma série de valores e de práticas que o programa tem o objetivo de divulgar e de legitimar, tais como aquelas vinculadas aos artistas urbanos ligados ao movimento e/ou à cultura hip hop.

Essa ancoragem, feita a partir do trabalho estratégico de seleção de um dos elementos do gênero "programa de auditório", o apresentador é mais um recurso, alinhado a uma série de outros recursos, como os acima descritos, de construção e manutenção da identidade social e referencial do programa (GRANATO, 2011). Há ainda um outro elemento do gênero "programa de auditório" que promove a manutenção da identidade referencial e social do Manos e Minas: os atores sociais que participam ativamente no palco e na plateia. Falaremos disso um pouco mais adiante.

Por fim, como estamos tratando de um programa de auditório, o cenário é um elemento importante que também ancora a identidade do programa. Esse cenário conta com painéis de arte urbana (grafite) e com uma passarela imitando o asfalto de uma rua, como podemos ver pela imagem abaixo:

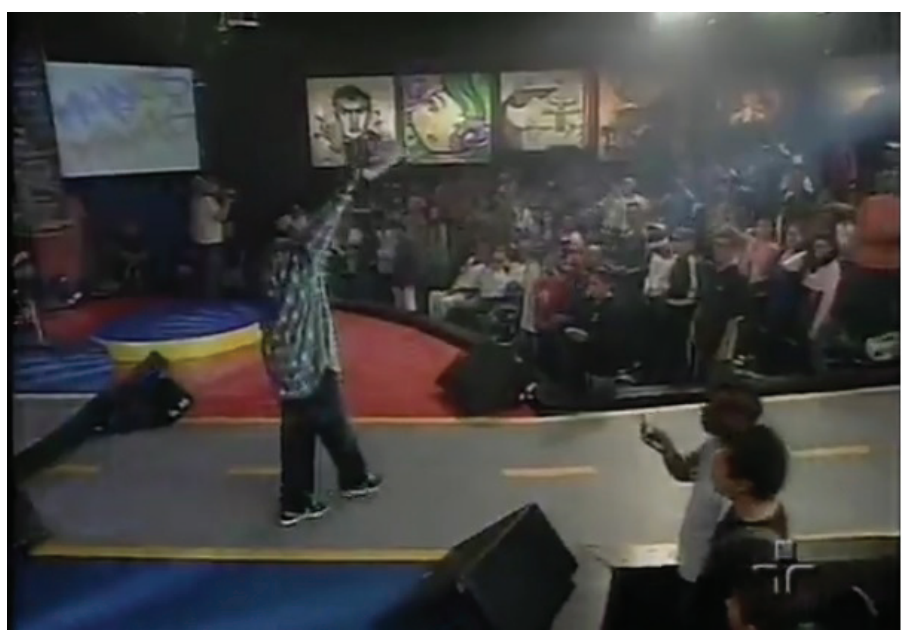

Figura 2: Cena da interação de Rappin Hood com a plateia, no Teatro Franco Zampari, no momento inicial do episódio de Manos e Minas exibido em 16/07/2008

Os atores sociais que participam ativamente no palco e na plateia são referenciados discursivamente pelo apresentador no primeiro minuto do programa, tal como pode ser observado na tabela abaixo: 


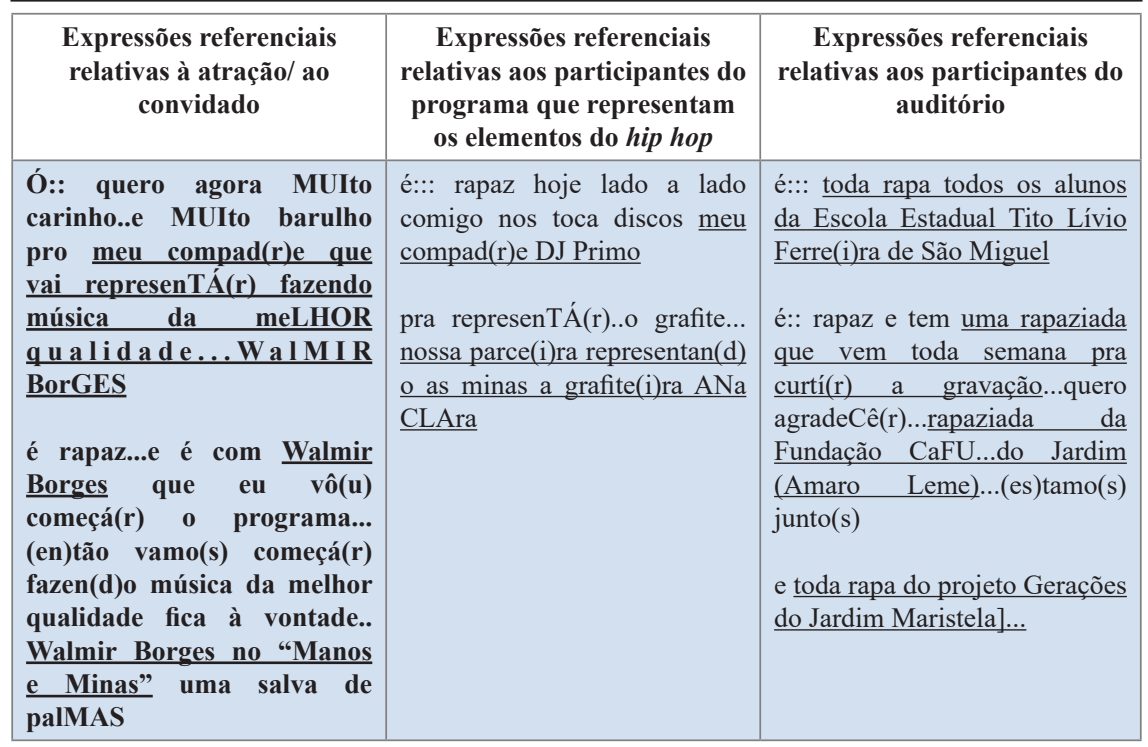

Tabela 1: Expressões referenciais relativas aos participantes do programa na introdução do episódio de Manos e Minas exibido em 16/07/2008.

As expressões nominais acima listadas (ver o Anexo 1 para a transcrição desse primeiro momento do programa) instauram novos referentes. Consideramos que a instauração desses novos referentes discursivos estabelece uma relação indireta com as expressões "manos" e "minas", dado que os referentes "rapa", "rapazidada", os nomes de vários bairros, escolas e projetos de São Paulo; são congruentes com a identidade social evocada pelo programa para seu público preferencial, que não apenas assiste ao programa, mas também tem a oportunidade de participar dele.

Sendo assim, as expressões nominais mobilizadas pelo apresentador para referenciar os indivíduos e as comunidades participantes do programa podem ser consideradas como anáforas indiretas em relação às expressões "manos" e "minas", dado que a relação entre os novos referentes e os referentes introduzidos se dá por meio de inferenciações culturais pressupostas pelo modelo textual ativado (MARCUSCHI, 2005, p. 79).

A nosso ver, os recursos acima descritos propiciam a construção de um tipo de representação da periferia a partir do programa organizada por três importantes eixos: os atores sociais (rappers, músicos, artistas urbanos, comunidades da periferia etc.), as práticas sociais (organizações sociais, projetos sociais, práticas artísticas e culturais etc.) e os espaços sociais (bairros, regiões, escolas, comunidades, ONGs etc.)

Nesse sentido, é possível afirmar que o conjunto de elementos de ancoragem da referência multimodal e social Manos e Minas também apresenta uma natureza multimodal e social. No entanto, é preciso esclarecer que esses 
elementos são produzidos em diferentes instâncias: por um lado, a instância do gênero do discurso, em que elementos do gênero "programa de auditório", trabalhados a partir de certas práticas sociais e culturais, auxiliam na ancoragem de um determinado programa, o Manos e Minas; por outro lado, a instância da textualidade, em que ações de textualização específicas (progressão referencial multimodal, envolvendo a ordenação de imagens e de expressões referenciais, de formas de interação verbal entre apresentador e plateia e de seleção de sonoridades musicais) também ancoram o programa como uma referência multimodal e social.

Todos esses elementos, gerados em diferentes instâncias discursivas (gêneros e textualidades), e que integram processos sociocognitivos e socioculturais complexos, possibilitam a emergência e manutenção do programa como uma referência social e multimodal, que consegue exibir a identidade descrita muito em função das lutas por legitimação dos "manos" e "minas" em outros campos sociais, para além do campo cultural da periferia.

\section{A CONSTRUÇÃO DO PROGRAMA CONEXÕES URBANAS COMO UMA REFERÊNCIA MULTIMODAL E SOCIAL}

Continuemos nosso exercício de análise da construção de um programa televisivo como uma referência multimodal e social. Consideraremos um outro gênero, o programa televisivo de reportagens ${ }^{11}$, mais especificamente, o programa Conexões Urbanas. No entanto, antes de começarmos a analisar um episódio específico, trataremos do idealizador, produtor e apresentador do programa, José Junior.

A nosso ver, o apresentador de um programa televisivo é um elemento importante da ancoragem de programas televisivos em geral. $\mathrm{O}$ apresentador do programa Conexões Urbanas é José Pereira de Oliveira Junior, ou José Junior (JJ), como é mais conhecido pelo grande público. Ele é, antes de tudo, o idealizador e produtor desse programa de reportagens. O conhecimento de sua trajetória ${ }^{12}$ é fundamental para a compreensão da imagem que se quer construir

${ }^{11}$ Consideramos que o Conexões Urbanas é um programa jornalístico televisivo que se configura, a cada episódio, como uma reportagem que enfoca uma determinada temática de forma mais aprofundada, apresentando, muitas vezes, "um caráter denunciante" (KOTSCHO, 2000, p. 71).

12 José Júnior sempre teve uma história marcada na e pela cidade do Rio de Janeiro, especificamente na Zona Norte. Desde criança, lidava com a violência dentro de sua própria casa, devido ao vício alcoólico de seu pai, à violência sofrida pela mãe e ao vício desta com o fumo. O crime sempre o acompanhou: já tentou roubar na infância, foi reprimido e detido diversas vezes pela polícia na adolescência e perdeu amigos para o tráfico de drogas. Após diversas empreitadas profissionais, como a promoção de festas funks e reggaes no centro do Rio de Janeiro, JJ criou, aos 25 anos, o jornal impresso "AfroReggae Notícias", com o intuito de descriminalizar as ruas e difundir a cultura afro pela cidade. A favela de Vigário Geral, cenário de toda sua infância e juventude, foi o local escolhido por Junior para iniciar seu maior trabalho, a criação do Grupo Cultural AfroReggae 
do programa. Em 1993, JJ criou o Grupo Cultural AfroReggae ${ }^{13}$. Segundo suas próprias palavras, "as pessoas me veem como um empreendedor bem-sucedido. Tudo que eu fiz na vida deu errado. Só fiz uma coisa que deu certo: o AfroReggae" (ERLANGER, 2015, p. 69). José Junior se tornou uma referência cultural para muitas pessoas, destacando-se como mediador de conflitos e auxiliador no trabalho de pacificação das favelas cariocas.

Após anos desenvolvendo diversas atividades com e para a população das periferias, José Junior ampliou sua atuação e deu início à produção de programas televisivos dentro da ONG. Um deles foi o Conexões Urbanas, que estreou em agosto de 2008, após ter tido como precursor um circuito musical de mesmo nome, criado em 2001 e com atuação até 2005.

Então, imaginemos que é a primeira vez que ligamos a TV para assistir a esse programa de reportagens. Diferentemente do programa de auditório descrito na seção anterior, o Conexões Urbanas não começa com uma vinheta. No caso do episódio específico aqui analisado, o programa se inicia com uma sequência de imagens de seu apresentador na interação com uma das participantes do programa, conforme podemos observar pela imagem abaixo:

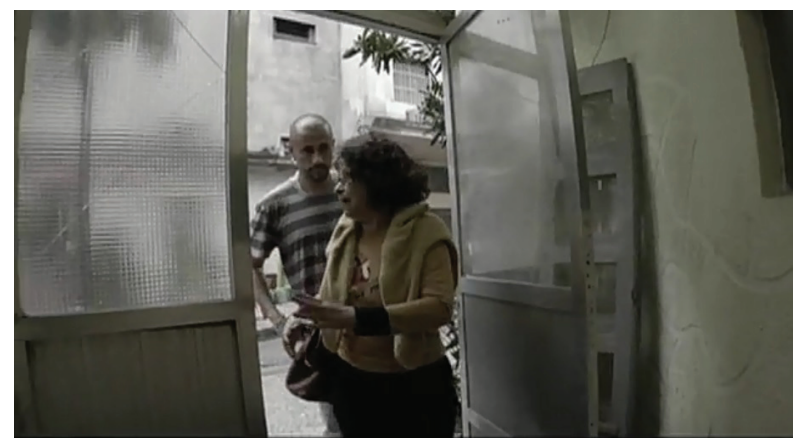

Figura 4: Cena do início do episódio Prostituição

${ }^{13}$ A criação do Grupo Cultural AfroReggae (GCAR) se deu em 21 de janeiro de 1993, com a festa de lançamento do "Jornal AfroReggae Notícias" n 0. A partir da inauguração de seu primeiro Núcleo Comunitário de Cultura, o Centro Cultural Waly Salomão, a instituição começou sua atuação social, e até hoje desenvolve projetos em áreas pobres, violentas e que muitas vezes são comandadas pelo tráfico de drogas nas favelas cariocas. A ONG tem como alvo as crianças e jovens que vivem em situação de exclusão, privação e vulnerabilidade social. Os projetos desenvolvidos pelo AfroReggae promovem a autoestima dos moradores de diversas comunidades, geram renda e os afastam da influência do tráfico. A ONG é considerada hoje uma referência para a promoção da igualdade de direito por meio de trabalhos socioculturais, pautada nos valores da diversidade, liberdade, transparência, inclusão e inovação. Com o destaque que o AfroReggae vem ganhando nos últimos tempos, principalmente após se reerguer dos atentados e ataques sofridos em 2013, ano em que também foi comemorado seus 20 anos de trabalho, a instituição abriu sua primeira sede fora do estado do Rio de Janeiro e organizou um escritório de representação em São Paulo. Além disso, o GCAR percorre outras partes do mundo, e seus projetos sociais já foram multiplicados em países como a Índia, Colômbia, China, Inglaterra, França e em Cabo Verde, na África, a convite da ONU. Mais informações sobre a instituição podem ser encontradas no livro Da favela para o mundo: A história do grupo cultural AfroReggae (2006), de autoria do próprio José Junior. 
Enquanto o apresentador adentra o prédio com sua interlocutora (imagem acima), sobe escadas e abre a porta de um apartamento, a voz dele, em "off", produz o texto transcrito abaixo:

\section{Exemplo 1}

JJ ((música de fundo)) ((cenas de JJ andando com GL)) meretriz prostituta mulher da vida rameira cortesã...garota de programa...PUTA munDAna PIranha...ostra quenga bisCAte...mulher-dama gaLInha rapaRIga POlaca vagaBUNda vaca perdida... PROfissional do amor

Em seguida, é exibida a vinheta do programa, conforme podemos observar pelos recortes das imagens abaixo:

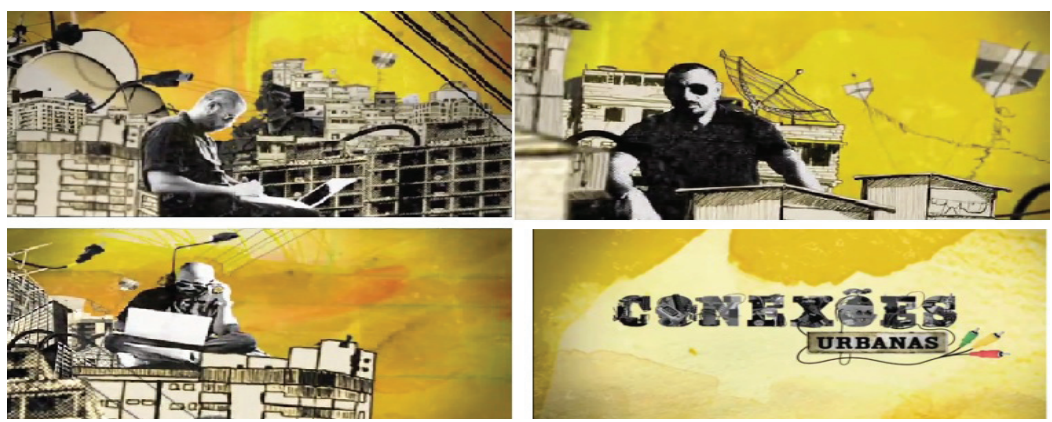

Figura 3: Cenas da vinheta do programa Conexões Urbanas

Após a vinheta, temos a introdução do título e, consequentemente, do tema a ser abordado nesse episódio:

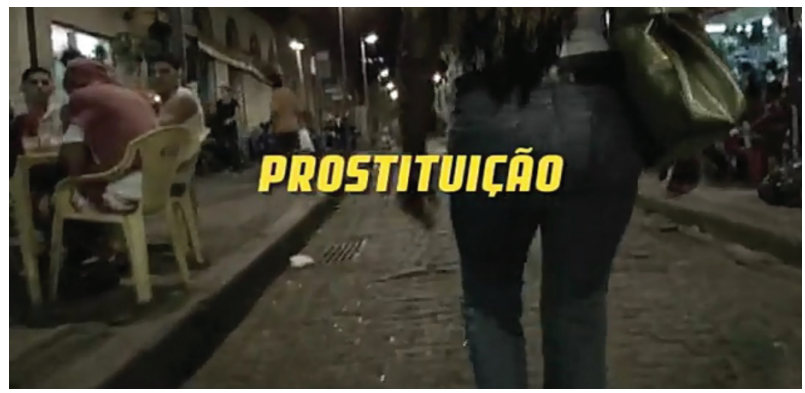

Figura 5: Introdução do título do episódio Prostituição

O principal elemento de ancoragem do programa é um elemento do gênero "reportagem televisiva ou eletrônica", a saber, o apresentador do programa. No entanto, diferentemente do que acontece no processo de ancoragem do programa Manos e Minas, o apresentador aqui é um elemento radial, a partir do qual todo o programa se estrutura: os programas têm início com o apresentador falando um breve texto que anuncia, de maneira mais ou menos direta, a temática do programa; em seguida, é exibida a vinheta do Conexões Urbanas, na qual a figura 
de José Júnior tem destaque. Sobre a vinheta, que se manteve a mesma até a quarta temporada do programa, observamos 17 segundos para sua exibição, com imagens de grafites que buscam representar a cena urbana (favelas e prédios), a partir de vários elementos que remetem tanto a como os espaços estão fisicamente organizados nas cidades como às práticas sociais e comunicativas das diferentes comunidades: moradias, antenas parabólicas, postes de iluminação, cabos,fios e pipas. Além disso, a vinheta do Conexões traz a figura de José Junior sobre esses desenhos, quase sempre com um computador à sua frente.

Como vimos nas imagens acima, o último quadro da vinheta traz o nome do programa destacado em caixa alta, sendo que cada letra é desenhada a partir de imagens de aparelhos eletrônicos, sobretudo câmeras de vídeo, cabos USB, plugues e tomadas. Alguns cabos envolvem as letras da palavra "Conexões" e algumas letras dessa palavra estão ligadas por fios/cabos à palavra "Urbanas". A vinheta como um todo reforça a ideia de conexão, de "elo", mais especificamente, os "elos" que José Júnior parece ter a responsabilidade de estabelecer principalmente entre os grupos periféricos e marginais e outros setores da sociedade, tal como afirma ao traçar os objetivos do programa.

Assim, os recursos multimodais que compõem a vinheta do programa e o papel desempenhado pelo apresentador a cada edição elaboram uma representação de José Júnior como agente das conexões produzidas entre diferentes setores da sociedade, atuando fortemente como um mediador de conflitos sociais.

O fato de o programa Conexões Urbanas ser uma das configurações do gênero "reportagem televisiva" pressupõe um outro elemento de ancoragem, para além do apresentador: a temática. De acordo com Bentes; Mariano; Accetturi (2015), os 110 episódios do Conexões Urbanas estão distribuídos em um conjunto de sete temáticas, que estiveram presentes de 2008 a 2015, período em que durou o programa.

Acreditamos que a construção do programa Conexões Urbanas como uma referência multimodal e social é tributária também de um trabalho linguísticodiscursivo bastante sistemático, especialmente no início do programa, por meio da elaboração de um título para cada episódio. Para os efeitos deste artigo, é importante retomar o texto inicial (Exemplo 1) falado por José Júnior com vistas a apresentar o principal tópico do episódio, a questão da prostituição.

São 19 expressões referenciais, cada uma construindo diferentes imagens para "prostituta", ator social evocado no título do programa. Também aqui, como no programa Manos e Minas, estabelece-se uma relação indireta entre as expressões referenciais que são enunciadas no início do programa e o título exibido depois. Se, por um lado, as expressões enunciadas, uma em seguida da outra, promovem um processo de recategorização contínua do referente "prostituta", por outro lado, o título promove um processo de sumarização e redirecionamento dos sentidos, dado que o foco passa de uma entidade (prostituta) para um processo (prostituição).

Para que possamos ter uma ideia um pouco mais detalhada da importância do elemento temático para a ancoragem do programa Conexões Urbanas, vejamos a tabela abaixo, que mostra as expressões referenciais que compõem o título de cada 
episódio do programa semanal ao longo do ano de 2008, considerando a relação entre as expressões e os atores sociais referidos, evocados ou não evocados.

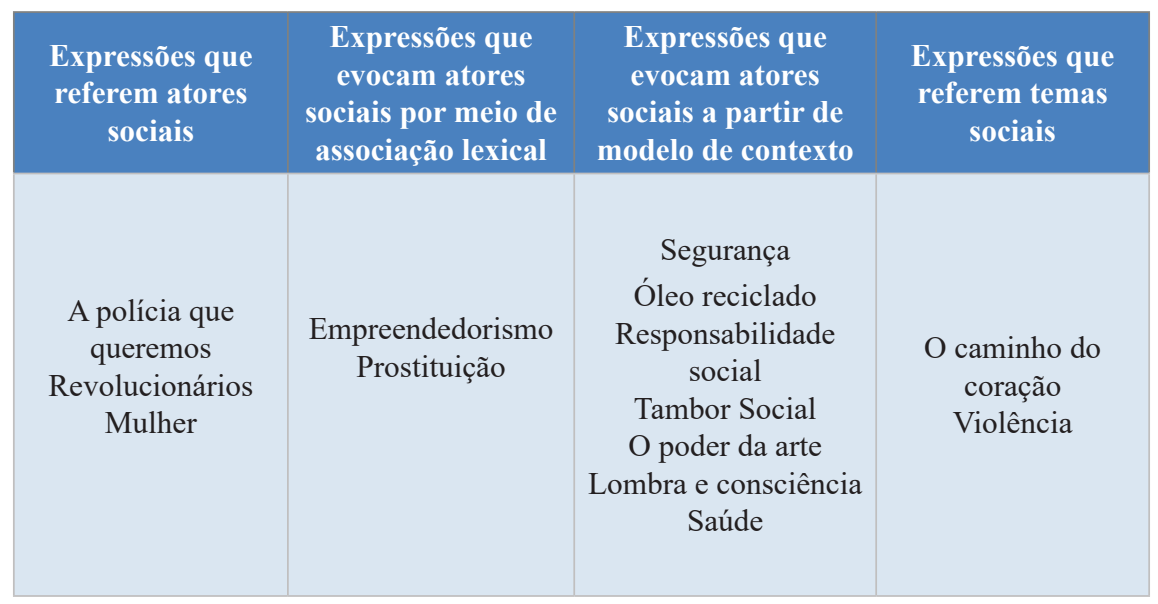

Tabela 2: Estratégias de introdução de referentes por expressões nominais no ano de 2008 (Adaptada de BENTES, MARIANO E ACCETTURI, 2015)

Não é nosso objetivo discutir os títulos do programa neste espaço. A apresentação da tabela acima pretende mostrar como essa estratégia de introdução referencial é fundamental para a contínua construção de uma identidade social para o programa, dado que as temáticas dessa primeira temporada estão concentradas na discussão sobre questões sociais importantes e polêmicas, tais como a questão da prostituição, projetos e ONGs e iniciativas individuais de sucesso.

As análises desenvolvidas por Bentes, Mariano e Accetturi (2015), após considerarem o percurso temático do Conexões Urbanas, parecem conduzir para um entendimento do programa como uma produção que busca enfatizar ações sociais e uma espécie de "sociedade-providência"14 que produzam alteração, mudança, diferença na sociedade e na periferia, alinhando-se ao pensamento conhecido como "empreendedorismo social" ("empreendedorismo" é, aliás, uma expressão que dá nome a uma das edições do programa nessa mesma temporada).

Tal especificidade da ancoragem construída pelo e para o programa se soma a outra característica mais específica do Conexões Urbanas já mencionada anteriormente, produzir uma representação do apresentador como um mediador entre os atores sociais da periferia e outros setores da sociedade.

${ }^{14}$ Uma referência ao conceito elaborado por Boaventura Souza (1995) para tratar de práticas da sociedade portuguesa e que, mais recentemente, tem sido discutido pelo sociólogo como conceito relevante para compreender sociedades de países semi-periféricos na regulação mundial. Ao referir-se à sociedade portuguesa, Santos (2016, p. 63) comenta o contraste entre um Estado-Providência fraco e uma sociedade-providência forte. 


\section{ALGUMAS CONCLUSÕES}

No início deste artigo, buscamos respostas para os seguintes questionamentos:

(i) quais processos de ancoragem possibilitam a construção referencial responsável, em parte, pela identidade social dos programas Manos e Minas e Conexões Urbanas e também pela emergência de determinadas categorizações no interior desses mesmos programas?

(ii) como essas ancoragens podem propiciar uma melhor compreensão sobre as relações entre a construção referencial dos/nos programas e o contexto social mais amplo a partir do qual essas específicas configurações genéricas emergem?

Em relação à primeira pergunta, é importante dizer que a construção dos programas Manos e Minas e Conexões Urbanas pressupõe processos complexos de ancoragem em elementos que são, a um só tempo, elementos dos gêneros aos quais são filiados e elementos do contexto social mais amplo. São esses processos que possibilitam a construção de ambos os programas como referências multimodais cuja identidade é reconhecida pelos grupos que pretendem representar e pelo público mais amplo.

Apesar de cada um dos programas constituir uma configuração genérica específica a partir dos gêneros "programa de auditório" e "reportagem televisiva ou eletrônica", em ambos a ancoragem ocorre a partir de um elemento comum aos dois gêneros, a saber, o apresentador.

$\mathrm{O}$ apresentador é peça central na construção dos programas como referências multimodais e sociais. Ambos os apresentadores, Rappin Hood e José Júnior, são elementos dos gêneros do discurso em questão e também são atores sociais influentes no campo midiático, legitimados pelo campo cultural e social da periferia, em função de suas trajetórias, como vimos ao longo das análises empreendidas.

No entanto, o papel desempenhado por esses atores sociais na construção de cada programa como um objeto-de-discurso é bastante diferente. Essa diferença tem como base o fato de que, no caso do programa Manos e Minas, importa o apresentador ser alguém que encarne e iconize os valores do movimento hip hop, tanto que outros rappers assumiram o papel de apresentador ao longo do tempo vale ressaltar que o programa continua sendo exibido até hoje. Já o apresentador do Conexões Urbanas assume individualmente o papel de mediador de conflitos entre diferentes grupos sociais. A identidade social do programa está fortemente vinculada a imagem pessoal de José Junior em função do fato de (i) ser ele o único apresentador do programa em todos os seus 111 episódios ao longo dos sete anos de sua exibição e (ii) de ser ele o idealizador e o produtor do programa, definindo os seus principais tópicos e participantes (BENTES; MARIANO; ACCETTURI, 2015; 2017).

A vinheta é um outro elemento dos gêneros televisivos de fundamental importância no processo de ancoragem dos programas como referências multimodais e sociais. No caso do programa Manos e Minas, a vinheta é estruturada 
a partir da estética e dos elementos característicos do movimento hip hop (grafite, MCs, DJs, b-boys, b-girls, grafiteiros), sem enfatizar um ator social em específico. Nesse programa, a vinheta, assim como as expressões referenciais utilizadas pelo apresentador Rappin Hood, parece funcionar como âncora que indicia os valores e as práticas da coletividade, isto é, do coletivo de um dentre outros grupos sociais que compõem a periferia urbana paulista e brasileira.

Já a vinheta do Conexões Urbanas enfatiza a figura de José Júnior (sua imagem aparece em quase todos os quadros que compõem a vinheta) e o conceito de "conexão" a partir das representações imagéticas de cabos, fios e antenas e computadores, que encarnariam a ideia de ligação, de conexão, entre os diversos grupos sociais e indivíduos mas, mais especialmente, entre grupos periféricos e outros setores da sociedade. Uma marca identitária importante para o programa, nesse caso, é a valorização da figura do apresentador, de sua posição social e de seu potencial como ator social, e o potencial de outros como ele para uma mudança ou transformação social por meio do empreendedorismo.

Ao fazermos o recorte analítico da introdução referencial para a elaboração dessa reflexão, observamos que a introdução de referentes verbais visualmente destacados é um recurso de ancoragem mobilizado apenas no programa Conexões Urbanas. Esse elemento de ancoragem verbo-visual contribui para o reforço da identidade social do programa, dado que as expressões referenciais mobilizadas indiciam temas socialmente relevantes que, na grande maioria das vezes, não são tratados de forma espetacular.

Respondendo, assim, a primeira pergunta, acreditamos que os processos de ancoragem pressupostos na construção referencial dos e nos programas são de natureza multimodal e social. Ao assumirmos que os processos de ancoragem envolvidos na construção referencial dos programas televisivos analisados são fundamentalmente multimodais, buscamos especificar a natureza dessa multimodalidade, descobrindo que alguns elementos estruturadores dos gêneros televisivos podem ser considerados como partes imprescindíveis dessa ancoragem (con)textual. A natureza social dos processos de ancoragem envolvidos na construção referencial dos programas televisivos analisados pode ser comprovada pelo fato de que, em cada um desses programas, são mobilizados atores sociais que possuem trajetórias específicas no interior do campo midiático, o que lhes permite "encarnar" os valores e as práticas dos grupos sociais que buscam representar, no caso, os grupos periféricos.

Desse modo, apesar de ambos os programas apresentarem elementos de ancoragem multimodal semelhantes (apresentador e vinheta), os contextos e práticas representados não são exatamente os mesmos, ainda que ambos busquem se construir como referências sociais para a periferia e como representantes da periferia frente a outros grupos sociais.

Em relação à segunda pergunta, é importante enfatizar que, ao falarmos dos programas como referências multimodais introduzidas, mantidas e continuamente reelaboradas por meio de processos de ancoragem em elementos oriundos dos gêneros e do contexto social mais amplo, reafirmamos o nosso compromisso com uma compreensão de que os referentes são construtos sociais que têm como 
principal função representar segmentos da realidade (MONDADA; DUBOIS, 2003) por meio de atividades de natureza não apenas linguística, mas também multimodal. No caso dos programas, eles são transformados em objetos-dediscurso quando referidos, por exemplo, pelos apresentadores, o que acontece mais frequentemente no início de cada programa, dado que as atividades referenciais de natureza discursiva são atos sociais necessariamente relacionados com as interações em curso (AGHA, 2007).

Sendo assim, ao longo deste artigo, procuramos mostrar que a noção de ancoragem, tal como desenvolvida no interior dos estudos textuais, pode ser vista de maneira um pouco mais ampliada, constituindo um tipo de processo (con) textual. É em função dessa postulação que reforçamos nosso entendimento de que os dados analisados podem ser considerados em pelo menos três dimensões, todas bastante imbricadas entre si: a dimensão textual, a dimensão do gênero discursivo e a dimensão do contexto social mais amplo no interior do qual os programas emergem. As descrições e análises desenvolvidas acima mostram como os programas televisivos apresentam uma dimensão textual, dado que se constituem em referências multimodais ao serem ancorados por elementos recuperáveis da superfície textual (apresentador, vinheta), elementos esses selecionados e trabalhados de maneira a introduzir e manter uma determinada identidade social e referencial para cada um dos programas. Além disso, a dimensão textual dos programas permite que sejam analisados como textos estruturados por cadeias referenciais nas quais os referentes ativados estão em relação direta ou indireta, tal como foi possível observar, por exemplo, na análise desenvolvida sobre as relações entre a expressão referencial "prostituição" e a cadeia de recategorizações da expressão referencial "prostituta", o que auxilia na construção dos sentidos sociais produzidos em cada episódio.

Os programas televisivos analisados podem ser considerados como configurações específicas dos gêneros "programa de auditório" e "reportagem televisiva", sendo justamente alguns elementos comuns aos dois gêneros o que possibilita uma ancoragem mais precisa dos programas. Nesse sentido, os processos de ancoragem são efetivados a partir dos elementos de uma instância discursiva como o gênero, este necessariamente parte de um contexto mais amplo, um campo social.

Por fim, os processos de ancoragem analisados podem ser considerados como uma das dimensões contextuais que configuram os textos e os gêneros do discurso, dado que os elementos que possibilitam a ancoragem referencial dos programas não apenas resultam de um trabalho social e multimodal detalhado, como também são moldados pelas trajetórias dos atores sociais que produzem e participam desse trabalho.

\section{REFERÊNCIAS BIBLIOGRÁFICAS}

ACCETTURI, A. C. A. Gêneros midiáticos e textualidade: o caso do programa Conexões Urbanas. Trabalho de Conclusão do Curso de Letras, Instituto de Estudos da Linguagem, Universidade Estadual de Campinas, Campinas, 2015, 60 p. 
AGHA, A. Language and social relations. Cambridge, MA: Cambridge, University Press, 2007, 427 p.

BAKHTIN, M. M. Estética da criação verbal. 4 ed. São Paulo: Martins Fontes, 2003, 476 p.

BENTES, A.C. Contexto e multimodalidade na elaboração de raps paulistas. Investigações, Recife, v. 21, n. 2, p.p. 199-220, 2008.

BENTES, A.C. Tudo que é sólido desmancha no ar: sobre o problema do popular na linguagem. Gragoatá, Niterói, v. 27, p. p. 12-47, segundo semestre de 2009.

BENTES, A.C. De frente para o 'campo de batalha': investigando as relações entre produção textual e contexto social no campo da cultura popular urbana paulista. In: BATTISTI, E.; COLLISCHONN, G. (Orgs). Lingua e linguagem: perspectivas de investigação. Rio Grande do Sul: EDUCAT, 2011, 324 p. p.p. 59-88.

BENTES, A.C. Temáticas como estratégias discursivas de legitimação social em programas televisivos brasileiros. no prelo.

BENTES, A. C. RIO, V. C. A construção conjunta da referência em uma entrevista semi-monitorada com jovens universitários. In: KOCH, I.G.V.; MORATO, E. M; BENTES, A.C. (Orgs.). Referenciação e discurso. 1. ed., São Paulo: Editora Contexto, 2005, 342 p. p. p. 265-292.

BENTES, A. C.; RAMOS, P. E.; ALVES FILHO, F. Enfrentando desafios no campo de estudos do texto. In: BENTES, A. C.; LEITE, M.Q. (Orgs.). Linguística de Texto e Análise da Conversação: panorama das pesquisas no Brasil. 1ed. São Paulo: Cortez Editora, 2010, 428 p. p.p. 07-13.

BENTES, A. C.; FERRARI, N. L. "E agora o assunto é trabalho": organização da experiência social, categorização e produção de sentidos no programa Manos \& Minas. Revista Diadorim, v. 10, p. p. 75-93, 2011.

BENTES, A. C.; FERREIRA-SILVA, B.; MARIANO, R. D. Atenuação e impolidez como estratégias estilísticas em contexto de entrevista televisiva. Cadernos de Letras da UFF. Niterói, n. 47, p. p. 285-314, 2013.

BENTES, A. C.; REZENDE, R. C. O texto como objeto de pesquisa. In: GONÇALVES, A. V. ; GOIS, M. L. S. (Orgs.). Ciências da linguagem: o fazer científico. Campinas, SP: Mercado de Letras, 2 v., 2014, 452 p. p.p. 137-176.

BENTES, A.C.; MARIANO, R.D.; ACCETTURI, A.C. Temas e estratégias referenciais em Conexão: analisando processos de estabilização e de mudança em um programa televisivo. ReVEL, v. 13, n. 25 , p. p. $316-354,2015$.

BENTES, A.C.; MARIANO, R.D.; ACCETTURI, A.C. "Eu quero muito trabalhar um tema": estratégias argumentativas no programa televisivo Conexões Urbanas". Signo, Santa Cruz do Sul, v. 42, n. 73, p. p. 110-123, 2017.

BOURDIEU, P. Razões práticas: sobre a teoria da ação. Campinas: Papirus, 1996, 231 p.

BOURDIEU, P. Sobre a televisão. Rio de Janeiro: Jorge Zahar, 1997, 143 p.

CAVALCANTE, M. M. Anáfora e dêixis: quando as retas se encontram In: KOCH, I.G.V.; MORATO, E. M; BENTES, A.C. (Orgs.). Referenciação e discurso. 1. ed., São Paulo: Editora Contexto, 2005, 342 p. p. p. $125-150$. 
CAVALCANTE, M. M. Referenciação: sobre coisas ditas e não ditas. 1. ed. Fortaleza: Edições UFC, 2011, $192 \mathrm{p}$.

ERLANGER, L. José Junior: no fio da navalha. São Paulo: Record, 2015, 280 p.

FERREIRA-SILVA, B. Metadiscursividade em entrevistas: a inscrição de Mano Brown no campo jornalístico. Dissertação (Mestrado em Linguística). Instituto de Estudos da Linguagem, Unicamp, Campinas, 2015, 278 p.

GRANATO, L. B. Gêneros discursivos em foco: dos programas televisivos Manos e Minas e Altas Horas. Dissertação (Mestrado em Linguística). Instituto de Estudos da Linguagem, Unicamp, Campinas, 2011, 353 p.

HANKS, W.F. Língua como prática social: das relações entre língua, cultura e sociedade a partir de Bourdieu e Bakhtin. In: BENTES, A.C.; REZENDE, R.C.; MACHADO, M.A. (Orgs.). São Paulo: Cortez Editora, 2008, 280 p.

JENKINS, H. Convergence Culture: Where Old and New Media Collide. New York: New York University Press, 308 p.

JUNIOR. J. Da favela para o mundo: a história do Grupo Cultural Afro Reggae. 2. ed. rev. e ampl. Rio de Janeiro: Ediouro, 2006, 279 p.

KOCH, I. G. V. Desvendando os segredos do texto. São Paulo: Cortez Editora, 2002, 168 p.

KOCH, I. G. V. Introdução à Linguística Textual: trajetória e grandes temas. São Paulo: Martins Fontes, 2004, $190 \mathrm{p}$.

KOCH, I. G. V. (2008). As tramas do texto. Rio de Janeiro: Nova Fronteira: Lucerna, 222 p.

KOCH, I.G.V.; MORATO, E. M.; BENTES, A.C. Referenciação e discurso. 1. ed. São Paulo: Editora Contexto, 2005, $337 \mathrm{p}$.

KOTSCHO, R. A prática da reportagem. 4. ed. São Paulo: Ática, 2000, 80 p.

KRESS, G.; VAN LEEUWEN, T. Multimodal discourse: the modes and media of contemporary communication. 1 reimpr. London: Bloomsbury Academic, 2010, 142 p.

MARCUSCHI, L. A. Anáfora indireta: o barco textual e suas âncoras. In: KOCH, I. G. V.; MORATO, E. M.; BENTES, A. C. (Orgs.) Referenciação e discurso. São Paulo: Editora Contexto, 2005, 342 p. p. p. $53-103$.

MARIANO, R. D. Marcadores discursivos e sequências textuais: uma análise das ações de textualização em programas midiáticos. Dissertação (Mestrado em Linguística). Instituto de Estudos da Linguagem, Unicamp, Campinas, 2014, 260 p.

MONDADA, L. Verbalisation de l'espace et danrication du savoir. Approche linguistique de la construction des objets de discurs. Lausanne: Thése pour obtenir lê grade de docteus em lettres, Faculte de Lettres, Université de Lausanne, Lausanne, 1994, 670 p.

MONDADA, L; DUBOIS, D. Construção dos objetos de discurso e categorização: Uma abordagem dos processos de referenciação. In: CAVALCANTE, M.M.; RODRIGUES, B.B.; CIULLA, A. (Orgs.). Referenciação. São Paulo: Editora Contexto, 2003, 249 p. p.p. 17-52. 
MORATO, E. M. et al. Processos implícitos, contextuais e multimodais na construção referencial em conversações entre afásicos e não afásicos: relato de pesquisa. Linguagem em (Dis)curso, Tubarão, SC, v. 12, n. 3, p. p. 711-742, set./dez. 2012.

MOURA, J. T. V.; SILVA, M. K. Atores sociais em espaços de ampliação da democracia: as redes sociais em perspectiva. Revista de Sociologia e Política, v. 16, número suplementar, p. p. 43-54, 2008 .

NASCIMENTO, E. P. do. É tudo nosso! Produção cultural na periferia paulistana. Tese (Doutorado em Antropologia). Faculdade de Filosofia, Letras e Ciências Humanas, Universidade Estadual de São Paulo, São Paulo, 2011, 214 p.

POCHMANN, M. Nova classe média?: o trabalho na base da pirâmide social brasileira. São Paulo: Boitempo Editorial, 2012, 127 p.

PRINCE, E. Toward a taxonomy of given-new information. In: COLE, Peter. (ed.) Radical pragmatics. New York: Academic Press, 1981, 328 p. p.p. 223-255.

SANTOS, B. de S. Sociedade-providência ou autoritarismo social? Revista Crítica de Ciência Sociais, n. 42, p.p. 1-4, 1995.

SANTOS, B. de S. A difícil democracia - reinventar as esquerdas. 1ed., São Paulo: Boitempo Editorial, $2016,224 \mathrm{p}$.

SCHIAVONI, J. E. Vinheta: uma questão de identidade na televisão. Dissertação (Mestrado em Comunicação), Universidade Estadual Paulista, Faculdade de Arquitetura, Artes e Comunicação, 2008, 129 p.

SILVA, R. S. A periferia pede passagem: trajetória social e intelectual de Mano Brown. Tese (Doutorado em Sociologia). Instituto de Filosofia e Ciências Humanas, Universidade Estadual de Campinas, Campinas, 2012, 302 p.

SOUZA, J. Uma nova classe trabalhadora brasileira?. In: SOUZA, J. (Org.) Os batalhadores brasileiros: nova classe média ou nova classe trabalhadora?. Belo Horizonte: UFMG, 2012, 354 p. p.p. $19-57$.

VAN DIJK, T. A. Discourse and Knowledge - a sociocognitive approach. 1. ed. Cambridge, Inglaterra: Cambridge University Press, v. 1., 2014, 400 p. 
ANEXO 1 - Introdução episódio de 16/07/2008 - Manos e Minas

\section{Part. Fala dos participantes}

((vinheta de abertura do programa))

PL $\quad{ }^{1}[($ (gritos, palmas, assobios no ritmo da música) $)]$

RH '[SALve SALve rapa "MAnos e Minas" (es)tá no a::r...mais uma semana graças a Deus aqui no teatro FRANco Zampari (es)tamo(s) junto(s)... "MAnos e Minas" na área...((cantando)) hã hã hã hã hã hã só os favelado(s) só os maloQUE(i)ro(s)]

PL $\quad{ }^{2}$ [os guerre(i)ro(s)...os guerre(i)ro(s)]

RH 2 [aHAN] na África de ANtes os PRÍNcipes herDE(i)ro(s).. ${ }^{3}[\mathrm{DI}:: \mathrm{z}]$

PL os gueRRE(i)ro(s)...3 [os gueRRE(i)ro(s)]

RH só os alia::do(s) só os companhe(i)ro(s) DI::z

PL os gueRRE(i)ro(s) os guerre(i)ros

RH eu mando aqui um salve pr'as parce(i)Ra(s) e pr'os parce(i)RO(s)

PL os gueRRE(i)ro(s)...os gueRRE(i)ro(s)

RH SALve SALve rapa "MAnos e Minas" (es)tá no $\operatorname{ar}^{4}[$ (es)tamo(s) junTO:.... isso MES:mo... sem paLAvras]

PL $\quad{ }^{4}[(($ risos, palmas e assobios $))]$

RH quero começá(r) JÁ...mandando um SALve...pra toda a rapaziada de SalvaDOR.. PORto Alegre... Tocantins... PIauí... Espírito SANtos ... GOiás... Amazonas... CeaRÁ... Paraíba... RIO de Jane(i)ro e SÃO PAulo.. ${ }^{5}[(\mathrm{es}) \operatorname{tamo}(\mathrm{s})$ JUNto]

PL $\quad{ }^{5}[(($ gritos e palmas $))]$

RH $\quad{ }^{6}[e ́:::$ rapaz] hoje lado a lado comigo nos toca discos meu compad(r)e DJ Primo

PL $\quad{ }^{6}[(($ gritos e palmas $))]$

RH [é::: rapa::z...] pra represenTÁ(r)..o grafite...nossa parce(i)ra representan(d)o as minas a grafite(i)ra ANa CLAra

PL $\quad{ }^{7}[(($ gritos e palmas $))]$

RH é:: rapaz e tem uma rapaziada que vem toda semana pra curtí(r) a gravação...quero agradeCê(r)...rapaziada da Fundação CaFU... ${ }^{8}$ [do Jardim (Amaro Leme)...(es)tamo(s) junto(s)]

PL $\quad{ }^{8}[(($ gritos e palmas $))]$

RH 9 [é::: toda rapa todos os alunos da Escola Estadual Tito Lívio Ferre(i)ra de São Miguel]

PL $\quad{ }^{9}[($ (gritos e palmas $\left.))\right]$

RH $\quad{ }^{10}[$ e toda rapa do projeto Gerações do Jardim Maristela]...

PL $\quad{ }^{10}[(($ gritos e palmas $))]$

RH Ó:: quero agora MUIto carinho..e MUIto barulho pro meu compad(r)e que vai represenTÁ(r) fazendo música da meLHOR qualidade... ${ }^{11}$ [WalMIR BorGES]

PL $\quad{ }^{11}[($ (gritos e palmas $\left.))\right]$

WB ${ }^{11}$ [obriga::do]

RH é rapaz...e é com Walmir Borges que eu vô(u) começá(r) o programa...(en)tão vamo(s) começá(r) fazen(d)o música da melhor ${ }^{12}$ [qualidade fica à vontade]..Walmir Borges no "Manos e Minas" uma salva de palMAS

Recebido: $12 / 03 / 2017$

Aceito: 08/04/2017 